\title{
Endotracheopulmonary Instillation, Suspension Dosage Form
}

National Cancer Institute

\section{Source}

National Cancer Institute. Endotracheopulmonary Instillation, Suspension Dosage Form.

NCI Thesaurus. Code C149493.

Liquid preparation consisting of an aqueous suspension intended for instillation to the trachea and/or bronchi. Preparations for inhalation use are excluded. 